\title{
ORIGINAL ARTICLE Effects of various food ingredients on gall bladder emptying
}

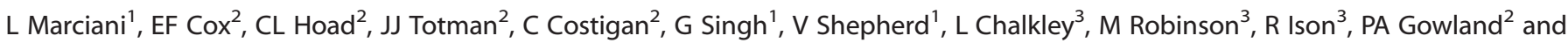 \\ RC Spiller ${ }^{1}$
}

BACKGROUND/OBJECTIVES: The emptying of the gall bladder in response to feeding is pivotal for the digestion of fat, but the role of various food ingredients in contracting the gall bladder postprandially is not well understood. We hypothesized that different food ingredients, when consumed, will have a different effect on stimulating gall bladder emptying. To investigate this we designed two randomized, investigator-blind, cross-over studies in healthy subjects using magnetic resonance imaging (MRI) to measure gall bladder volumes serially and non-invasively.

SUBJECTS/METHODS: Study 1: exploratory study evaluating the effects of 10 different food ingredients on gall bladder emptying in eight healthy subjects. The choice of ingredients varied from common items like coffee, tea and milk to actives like curcumin and potato protease inhibitor. Study 2: mechanistic study investigating the cholecystokinin (CCK) dose response to the best performer ingredient from Study 1 in 21 healthy subjects four ways.

RESULTS: The largest gall bladder volume change in Study 1 was observed with fat, which therefore became the dose-response ingredient in Study 2, where the maximum \% gall bladder volume change correlated well with CCK.

CONCLUSIONS: These serial test-retest studies showed that the fasted gall bladder volume varied remarkably between individuals and that individual day-to-day variability had wide coefficients of variation. Improved knowledge of how to stimulate bile release using food ingredients will be useful to improve in vitro-in vivo correlation of bioavailability testing of hydrophobic drugs. It could improve performance of cholesterol-lowering plant stanol and sterol products and possibly aid understanding of some cholesterol gallstone disease.

European Journal of Clinical Nutrition (2013) 67, 1182-1187; doi:10.1038/ejcn.2013.168; published online 18 September 2013

Keywords: MRI; CCK; gall bladder; ejection fraction; fat

\section{INTRODUCTION}

The gall bladder stores and concentrates bile salts during fasting and releases them into the duodenum in response to gastric emptying of a meal. ${ }^{1}$ The flow of bile into the duodenum is controlled by gall bladder muscular contraction, gall bladder tone, hepatic secretory pressure and relaxation of the sphincter of Oddi. $^{2}$ This process is mostly regulated by the hormone cholecystokinin (CCK) that is released by the proximal intestine in response to products of macronutrients digestion, particularly fat. ${ }^{3-8}$ Although there is good knowledge of other secretory responses to dietary composition, such as pancreatic exocrine secretion, the effect of various food ingredients on gall bladder emptying has been explored to a much lesser extent. Specific food ingredients could be effective to trigger gall bladder emptying including dietary protein that stimulates CCK secretion, ${ }^{9,10}$ curcumin that increases gall bladder emptying ${ }^{11}$ and protease inhibitors that potentiate the CCK response to nutrients. ${ }^{12}$ Widely consumed beverages such as coffee can also be effective, ${ }^{13}$ but which food ingredients are most effective in contracting the gall bladder is not well understood. Increased knowledge would be desirable for many reasons. Bile secretion in the duodenum is key to lipid digestion. ${ }^{14,15}$ The presence of mixed micelles of bile salts ${ }^{16}$ with lipolysis products may have an impact on the performance of highly hydrophobic, low solubility (classes II and IV biopharmaceutics drug classification system, $\mathrm{BCS},{ }^{17}$ ) compounds; ${ }^{18,19}$ it also has an impact on the ability of plant stanol and sterol products to block dietary cholesterol and the recirculation of endogenous cholesterol ${ }^{20,21}$ thereby lowering levels of plasma cholesterol. Further, impaired gall bladder emptying has been linked with the pathogenesis of cholesterol gallstones. ${ }^{22}$

The main hypothesis here was that different food ingredients, when consumed, will have a different effect on stimulating gall bladder emptying. To investigate this we designed two randomized, investigator-blind, cross-over studies in healthy subjects using magnetic resonance imaging (MRI) to measure gall bladder volumes serially and non-invasively. Study 1 was an exploratory study evaluating the effects of 10 different food ingredients on gall bladder emptying in eight healthy subjects. The ingredients selected were all approved for use in the EU, a mix of technology and occasion driven food ingredients, and were chosen based on their potential ability to stimulate gall bladder emptying. Study 2 was a mechanistic study aiming at investigating the CCK dose response to the best performing ingredient from Study 1 . These studies would also provide insights on normal fasting gall bladder volume ranges and their coefficients of variation.

\section{SUBJECTS AND METHODS}

Study design

Both studies obtained local University Medical School Research Ethics Committee approval, and all subjects gave informed written consent. The study was carried out according to Good Clinical Practice principles. All test

${ }^{1}$ Nottingham Digestive Diseases Centre and NIHR Nottingham Digestive Diseases Biomedical Research Unit, University of Nottingham, Nottingham, UK; ${ }^{2}$ Sir Peter Mansfield Magnetic Resonance Centre, School of Physics and Astronomy, University of Nottingham, Nottingham, UK and ${ }^{3}$ Johnson \& Johnson Consumer Services EAME Ltd, Maidenhead, UK. Correspondence: Professor RC Spiller, Nottingham Digestive Diseases Centre and NIHR Nottingham Digestive Diseases Biomedical Research Unit, Queen's Medical Centre, E Floor, West Block, Nottingham University Hospitals, University of Nottingham, Nottingham NG7 2UH, UK. 
products, Case Report Forms and study monitoring were provided by the sponsor.

The inclusion criteria were male or female, 18-45 years of age, healthy, with body mass index (BMI) $20-30 \mathrm{~kg} / \mathrm{m}^{2}$. Exclusion criteria comprised pregnancy, any history of serious acute or chronic illnesses, alcohol and/or substance abuse, the presence of implant or devices in the body that are contraindicated for MRI (for example, pace makers, metal implants), use of medication that may interfere with gastrointestinal physiology and the use of sterol/stanol margarine and/or fiber supplement 30 days before and/or during the course of the study. The subjects were instructed to fast overnight for at least $8 \mathrm{~h}$ before the study period. On each study day, they filled in a questionnaire to confirm they followed study restrictions and eligibility.

The operator who processed the data was kept blinded to the randomization code by the investigator who dispensed the test meals and saved the image files from the MRI scanner in a blind manner. The code was broken only after data processing and blind data review were completed.

The MRI images were used to calculate the volume of the gall bladder at each specified time interval as described below, and the percentage (\%) of gall bladder volume change from baseline and the area under the curve (AUC) between $t=-5$ and $t=65$ min were derived.

The primary end point was the maximum \% gall bladder volume change between $t=-5$ and $t=65 \mathrm{~min}$ by test product. This was chosen as primary end point, as it takes into account the maximum gall bladder volume change occurring over the whole postprandial period investigated and also normalizes each subject's gall bladder to the starting fasted time point on each study day, making it easier to carry out comparisons in these multiple ways studies.

The secondary end points were the gall bladder volume for each individual time point by test product, the \% gall bladder at volume change at $t=45 \mathrm{~min}$, the AUC for gall bladder volume and the time to maximum gall bladder volume change.

\section{Study 1}

Eight subjects were recruited and they all completed the 10-way study. They were five men and three women, $26.5 \pm 8$ years old with BMI $22.5 \pm 0.6 \mathrm{~kg} / \mathrm{m}^{2}$.

The subjects consumed one of 10 test products at each of the 10 test visits (one week apart from each other) based on a computer-generated randomization schedule. The products comprised emulsions, yogurt, coffee, tea and semi-skimmed milk as specified in Supplementary Table 1. At each test visit, an MRI scan of the abdomen encompassing the gall bladder was obtained at fasted baseline before consumption of the food product $(t=-5 \mathrm{~min}$ ) and after that at times $t=5,15,25,35,45$, 55 and 65 min post ingestion of the test product, for a total of eight scans at each visit. Additional analysis investigated the correlation of maximum $\%$ gall bladder volume change between $t=-5$ and $t=65 \mathrm{~min}$ with fat, protein and volume characteristics of the test products.

\section{Study 2}

Twenty-two subjects were recruited. One subject withdrew after two occasions, and hence 21 subjects completed the 4-way study. They were 11 men and 10 women, $27 \pm 8$ years old with body mass index (BMI) $22.5 \pm 0.6 \mathrm{~kg} / \mathrm{m}^{2}$. Four of these 21 subjects failed to give at least one blood sample (for example because a blocked cannula) so there were $n=17$ completed subjects available for the plasma CCK analysis.

The subjects consumed one of four test products at each of the four test visits (1 week apart from each other) based on a computer-generated randomization schedule. The products comprised milk-based, ready-todrink beverages based on the results of Study 1 . They were $150 \mathrm{ml}$ milkbased drinks that contained the same amount of protein $(9 \mathrm{~g})$ and the same amount of plant stanol ester $(2.23 \mathrm{~g})$ but increasing amounts of fat $(1.5 \mathrm{~g}, 3.5 \mathrm{~g}, 6.5 \mathrm{~g}, 10 \mathrm{~g}$ fat, respectively).

At each test visit, an intravenous cannula was inserted in a forearm vein by an experienced research nurse. A MRI scan of the abdomen encompassing the gall bladder was obtained at fasted baseline before consumption of the food product $(t=-5 \mathrm{~min})$ and after that at times $t=5,15,25,35,45,55$ and 65 min post-ingestion of the test product, for a total of eight scans at each visit. After each MRI scan, a blood sample was drawn from an intravenous cannula for CCK analysis.

Additional secondary end points for this study were maximum plasma CCK between $t=5 \mathrm{~min}$ and $t=65 \mathrm{~min}$, plasma CCK at $t=45 \mathrm{~min}$ and correlation between maximum CCK levels and maximum $\%$ gall bladder volume change between $t=5 \mathrm{~min}$ and $t=65 \mathrm{~min}$.

\section{Magnetic resonance imaging}

MRI was carried out on a 1.5T Philips Achieva (Philips Healthcare, Eindhoven, The Netherlands) whole body scanner using the whole body Transmit/Receive coil. Each subject was positioned supine in the scanner. A coarse scout scan was run to locate the position of the gall bladder and plan the position of the image planes for the following data acquisition scan. Coronal, single-shot, turbo spin-echo MRI images were then acquired with spectral presaturation with inversion recovery fat suppression. This imaging sequence was heavily T2-weighted so that liquid appears very bright and the rest of the surrounding organs appear quite dark. They comprised 30 contiguous slices with no gap, echo time $\mathrm{TE}=4.4 \mathrm{~ms}$ with echo spacing $4.4 \mathrm{~ms}$, acquisition matrix $268 \times 198$ and flip angle $90^{\circ}$ and an acquired in-plane resolution of $1.5 \times 1.5 \mathrm{~mm}^{2}$ and a slice thickness of $6 \mathrm{~mm}$ (reconstructed $0.78 \times$ $0.78 \times 6 \mathrm{~mm}^{3}$ ). They were acquired in a single breath-hold of $26 \mathrm{~s}$. The MRI scanning schedule allowed interleaving two subjects per morning thus increasing throughput and reducing cost.

\section{Plasma collection and CCK assay}

On arrival an 18-gauge BD Venflon Pro (Becton Dickinson Infusion Therapy, Helsingborg, Sweden) intravenous cannula was placed in a forearm vein of the subjects. $6.5-\mathrm{ml}$ blood samples were collected fasted and at each postprandial scanning time point. The blood was transferred immediately into chilled blood collection tubes containing $0.3 \mathrm{ml}$ ethylenediamine tetra-acetic acid and $5000 \mathrm{KIU}$ aprotinin. The samples were cooled in an ice-bath immediately. The plasma was then readily separated by centrifugation for $10 \mathrm{~min}$ at $3000 \mathrm{~g}$ at $4^{\circ} \mathrm{C}$. The separated plasma was collected using a plastic pastette and transferred to clean tubes for immediate storage at $-80^{\circ} \mathrm{C}$ until assayed using radioimmuno assay with commercially available kits according to the manufacturer's instructions (EURIA-CCK, Euro-Diagnostica, obtained from Immunodiagnostic Systems, Ids Ltd., Tyne and Wear, UK) as described previously. ${ }^{8}$

\section{Data analysis, statistical methods and power of the studies}

The image data set from each subject and each time point was recalled on a workstation and commercial software (Analyze 6, Biomedical Imaging Resources, Mayo Clinic, Rochester, MN, USA) was used to trace around the gall bladder a region of interest on each image slice using the 'Smart Edge' function. This function is commonly used as it searches for areas of high gradient to adjust the path of the region of interest, thus aiding the operator semi-automatedly. The gall bladder volume was then calculated by summing across all region of interests for that given subject and time point. These were tabulated and plotted in the Microsoft Excel to determine time courses and to calculate the AUC using the trapezoidal method. The $\%$ gall bladder volume change was calculated as $(1-$ gall bladder volume at time $t /$ gall bladder volume at baseline) $\times 100$ expressed in $\%$ and with time $t$ defined as the time of imaging postprandially (that is, between 5 and $65 \mathrm{~min}$ ).

As shown by Shapiro Wilk's test, the vast majority of the data were normally distributed and were expressed as mean \pm s.e.m. Accordingly, parametric statistic tests were used to assess the significance of the effect of test products and time on the end point measures, followed by post hoc Dunnett's test corrected for multiple comparison comparing all test products versus the 4-ml high-fat emulsion in Study 1 and versus the least fatty sample in Study 2. As this was a cross-over study design, each subject acted as his/her own control. The CCK plasma values were not normally distributed even after log transform, and hence for these a 2-way ANOVA was not performed. Differences were being significant at $P<0.05$. GraphPad Prism version 4 (GraphPad Software Inc, La Jolla, CA, USA) was used throughout.

Study 1 was an exploratory study, and hence a power calculation of sample size was not available. On the basis of the results of Study 1 in which the semi-skimmed milk drink achieved a mean maximum $\%$ gall bladder volume change of $41 \%$ with an s.d.of $9 \%$, it should be possible to detect a difference in maximum gall bladder volume change of $15 \%$ with $P<0.05$ and a $90 \%$ power using $n=22$ subjects. 


\section{RESULTS}

The study procedures were well tolerated and all subjects completed the studies, but one subject in Study 2 withdrew after two study days for personal reasons. Imaging subjects with an MRI scanner in-built body coil was very rapid, requiring no positioning of additional abdominal receivers on the subjects or parallel imaging calibration scans, while providing images of good quality for gall bladder volume measurements as shown by an example in Figure 1.

\section{Study 1}

The primary end point was the maximum $\%$ gall bladder volume change between $t=-5$ and $t=65 \mathrm{~min}$. This was significantly different between test products as shown in Figure $2(P<0.0001)$. The $20 \mathrm{ml}$ high-fat emulsion yielded the largest gall bladder volume change $(42 \%)$, and this was significantly larger than for all the other test products $(P<0.05)$ apart from the $250 \mathrm{ml}$ semiskimmed milk ( $41 \%$ volume change, $P>0.05$ ) and the $4 \mathrm{ml}$ highfat emulsion ( $27 \%$ volume change, $P>0.05$ ). Comparing drinks with equal volumes showed that the semi-skimmed milk achieved a significantly higher maximum \% gall bladder volume change than coffee $(22 \%)$ and tea $(18 \%)(P<0.05$ for both). All data are summarized in Supplementary Table 1.

Looking at the other outcomes, there was a significant effect on gall bladder volumes by meal $(P<0.0001)$. There was a significant effect of meal type on gall bladder emptying as measured by AUC of the volume curves $(P<0.0001)$ and also as \% gall bladder volume change at $t=45 \mathrm{~min}(P<0.0006)$. The maximum $\%$ gall bladder volume change correlated significantly with fat content $(r=0.80, P<0.0052)$ but not with protein content $(r=0.41, P<0.2)$ or drink volume $(r=0.13, P<0.7)$. The slope of the line to the maximum gall bladder volume change was the highest for the milk, indicating the fastest emptying response, while the high-fat emulsion meals yielded a lower slope value, indicating a slower (albeit deeper) gall bladder emptying.

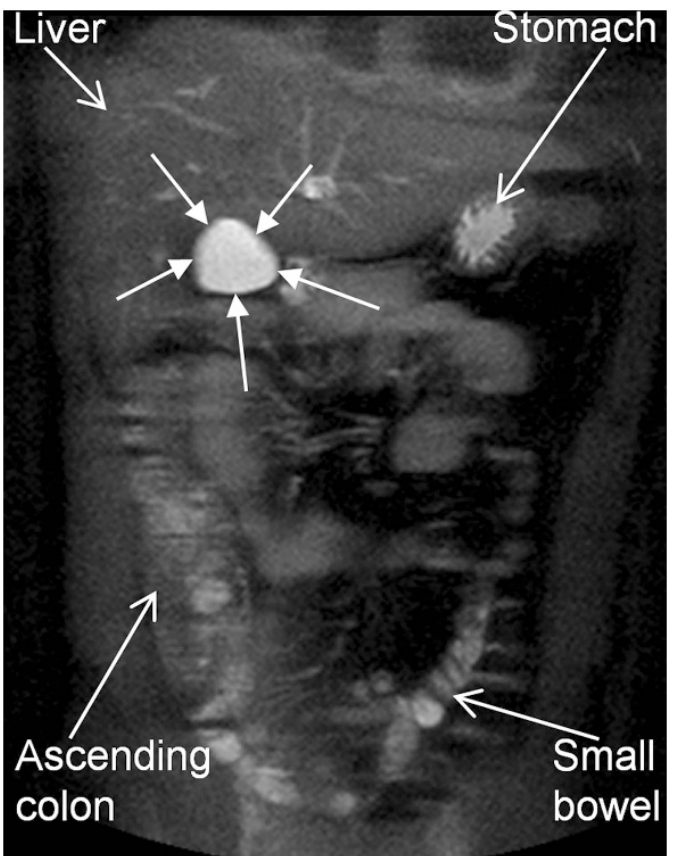

Figure 1. Representative example of a coronal, single-shot, turbo spin-echo magnetic resonance image taken across the fasting gall bladder (indicated by the closed arrows) of a healthy volunteer. In this heavily T2-weighted imaging sequence the liquid in the gall bladder appears very bright and the rest of the surrounding organs appear quite dark aiding data processing.
Study 2

We confirmed previous work showing that, of all the ingredients tested, fat produced the strongest gall bladder response with a maximum \% gall bladder volume change dose response to fat $(P<0.003)$. The least amount of fat $(1.5 \mathrm{~g})$ achieved already a mean maximum percentage gall bladder volume change of $33 \%$. The drinks containing $6.5 \mathrm{~g}$ and $10 \mathrm{~g}$ fat achieved significantly higher maximum \% gall bladder volume change ( $P<0.01$ for both). The mean maximum $\%$ gall bladder volume change data are plotted in Figure 3 and the other data are summarized in Supplementary Table 2.

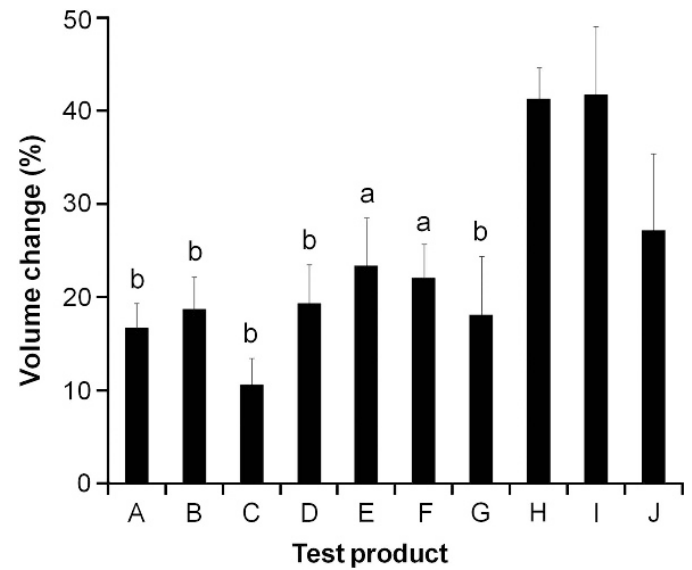

Figure 2. Maximum \% gall bladder volume change between $t=-5$ and $t=65 \mathrm{~min}$ for healthy volunteers after they consumed each of the 10 test ingredients in Study 1. Values are mean \pm s.e.m., $n=8$. $\mathrm{A}=25 \mathrm{ml}$ dairy emulsion; $\mathrm{B}=25 \mathrm{ml}$ dairy emulsion $+300 \mathrm{mg}$ potato protease inhibitor; $C=67.5 \mathrm{~g}$ yogurt drink; $\mathrm{D}=67.5 \mathrm{~g}$ yogurt drink $+3 \mathrm{~g}$ protein; $\mathrm{E}=67.5 \mathrm{~g}$ yogurt drink $+80 \mathrm{mg}$ curcumin; $\mathrm{F}=250 \mathrm{ml}$ coffee; $\mathrm{G}=250 \mathrm{ml}$ tea; $\mathrm{H}=250 \mathrm{ml}$ semi-skimmed milk; $\mathrm{I}=20 \mathrm{ml}$ high-fat emulsion; and $\mathrm{J}=4 \mathrm{ml}$ high-fat emulsion. ${ }^{a}$ Significant difference versus ingredient $\mathrm{J}, 4 \mathrm{ml}$ high-fat emulsion $(P<0.05)$; ${ }^{b}$ Significant difference versus ingredient $\mathrm{J}, 4 \mathrm{ml}$ high-fat emulsion $(P<0.01)$.

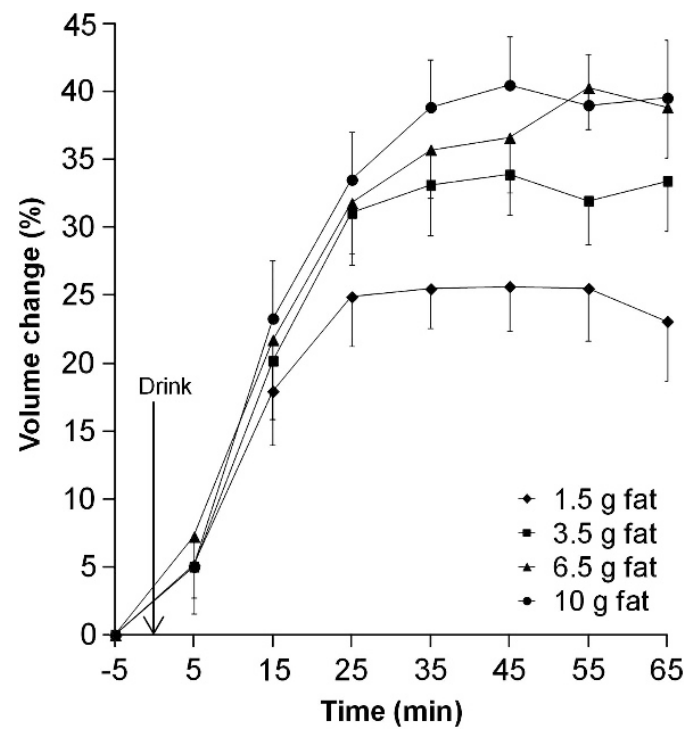

Figure 3. Plot of the $\%$ gall bladder volume change with time for healthy volunteers after they consumed each of the four milk-based beverages of increasing fat content in Study 2. Values are mean \pm s.e.m., $n=21$. 
Looking at the other outcomes, there was a significant effect of fat content on gall bladder volumes $(P<0.0001)$.

There was a significant effect of meal fat on gall bladder emptying as measured by AUC of the volume curves $(P<0.01)$ and also as $\%$ gall bladder volume change at $t=45 \mathrm{~min}(P<0.0008)$.

There was a dose response of the effect of meal fat on maximum plasma CCK levels $(P<0.007)$. There was a significant effect of meal fat on plasma CCK as measured by overall AUC (Figures $4, P<0.004)$ and on plasma CCK at $t=45 \mathrm{~min}(P<0.0008)$.

The maximum \% gall bladder volume change correlated significantly with the maximum plasma CCK (Spearman's $r=0.42, P<0.0001)$.

Fasting gall bladder volumes normal ranges

The test-retest repeated Studies 1 and 2 yielded also a unique collection of fasting gall bladder volumes that enable assessment of size and inter- and intra-subject variability. The individual data are shown in Figure 5. The mean volume of the fasted gall bladder per subject showed wide variability between $12 \mathrm{ml}$ and $52 \mathrm{ml}$ with test-retest coefficients of variation ranging between 3\% and $42 \%$. The overall mean of the individuals' mean fasted gall bladder volumes was $26 \pm 2 \mathrm{ml}$. There was a strong correlation of mean gall bladder size with subjects' weight $(r=0.68, P<0.0001)$, height $(r=0.50, P<0.006)$ and BMI $(r=0.48, P<0.008)$ but not with age $(r=0.12, P<0.5)$.

\section{DISCUSSION}

The emptying of the gall bladder has been studied using gamma scintigraphy or ultrasound techniques. ${ }^{3,4,23-29}$ In recent years, MRI has been shown to measure serially the emptying of the gall bladder accurately, non-invasively and with high spatial resolution. ${ }^{30-34}$ In these studies, serial MRI performed well and it was an effective, non invasive and accurate way of monitoring the effects of various food products on gall bladder emptying.

The main hypothesis of Study 1 that different food ingredients will have a different effect on stimulating gall bladder emptying was proven to be correct. The choice of ingredients varied from common (occasion driven) items like coffee, tea and milk to

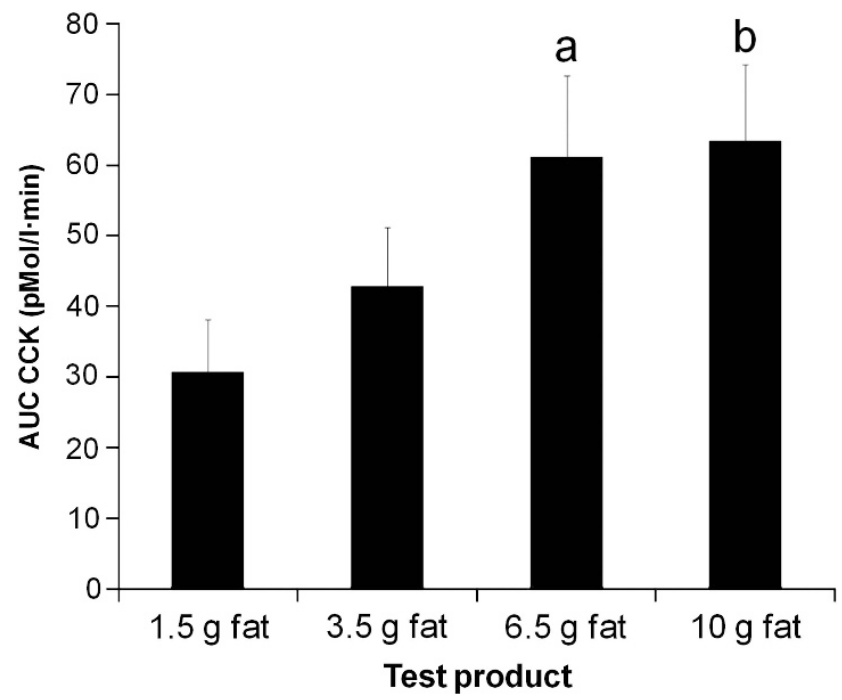

Figure 4. Area under the curve (AUC) for plasma cholecystokinin (CCK) for healthy volunteers after they consumed each of the four milk-based beverages of increasing fat content in Study 2. Values are mean \pm s.e.m., $n=17$. ${ }^{a}$ Significant difference versus $1.5 \mathrm{~g}$ fat drink $(P<0.05)$; ${ }^{\text {b }}$ Significant difference versus $1.5 \mathrm{~g}$ fat drink $(P<0.01)$. actives like curcumin and potato protease inhibitor (food manufacturing driven).

Semi-skimmed milk performed well but it is difficult at this stage to discriminate whether its composition of fat and protein would have an additive effect in contracting the gall bladder. The protein contribution would need to be the subject of future studies.

The largest gall bladder volume change was observed with the positive fat-containing control ( $20 \mathrm{ml}$ of high-fat emulsion). However, gall bladder emptying induced by amounts of fat as low as $7 \mathrm{~g}$ (perfused in the jejunum) ${ }^{35}$ had been observed previously. Our data show that a very low amount of fat $(2 \mathrm{~g}$ fat in $4 \mathrm{ml}$ of high-fat emulsion) nevertheless achieved a marked gall bladder volume change of $27 \%$. The potato protease inhibitor achieved a modest gall bladder volume change. The same potato protease inhibitor did not significantly affect healthy volunteers' plasma CCK at twice the dose we used. ${ }^{36}$ The $80 \mathrm{mg}$ curcumin stimulus was the fourth best performer achieving a mean $23 \%$ maximum gall bladder volume change. This was, however, much lower than the $40 \%$ volume change reported at $1 \mathrm{~h}$ in a previous ultrasonography study. ${ }^{37}$ Whether the reason for this difference might rest on the different imaging technologies used or in the delivery vehicle (a yogurt drink in our study versus plain curcumin ingested with a glass of water in that report) is unclear. When looking at the correlation with meal components, the maximum \% gall bladder volume change correlated positively and significantly with the fat content of the samples (with or without the stanol included in the calculation, Pearson's $P<0.0052$ and $P<0.0012$, respectively) but neither with the protein nor with the volume of the meals.

The main conclusion from this initial scouting study was that long-chain fat with a high degree of emulsification was the best performer in stimulating gall bladder emptying, likely to be explained with current knowledge ${ }^{2}$ via the cholecystokinin (CCK) duodenal response and to be tested in our second study. Semiskimmed milk performed well and this was one of the reasons driving the choice of a milk-based beverage as vehicle for increasing amounts of emulsified fat, while keeping protein and volume the same, in Study 2. Protein is also a potent stimulant of CCK, whereas carbohydrate is not. ${ }^{10}$ Gastric emptying of stable fat emulsions is slow ${ }^{8}$ that may be a factor contributing to the longest time to maximum gall bladder volume change shown by the $20 \mathrm{ml}$ high-fat emulsion.

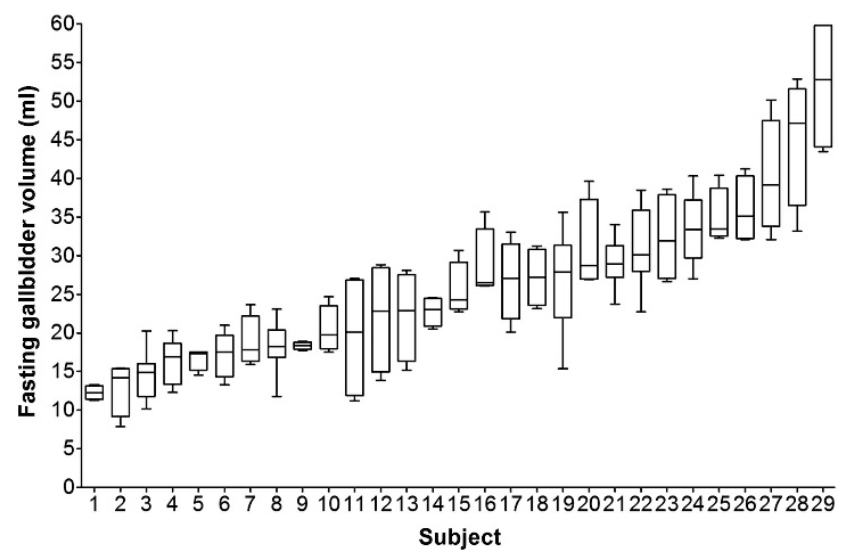

Figure 5. Box and whiskers plot of the individual fasting gall bladder volumes for the eight healthy volunteers in Study 1 and the 21 volunteers in Study 2. For each participant, the box represents the 25 and 75 percentiles, the horizontal line in the box represents the median value and the whiskers represent the minimum and maximum gall bladder volume. 
The main hypothesis of Study 2 that the best performer of Study 1 (emulsified fat in this case) will have a dose response effect on maximum \% gall bladder volume change was correct. This correlated well with increased plasma CCK levels in keeping with the well-established role of fat in releasing CCK, which depends on fatty acid chain length, ${ }^{38,39}$ and the role of CCK in regulating gall bladder emptying. ${ }^{40}$ Interestingly the milk-based beverage with the lowest amount of fat $(1.5 \mathrm{~g})$ achieved already a marked mean maximum percentage gall bladder volume change of $33 \%$ over the length of time investigated. Our meals were all low calorie (for example, $90 \mathrm{kcal}$ for the $20 \mathrm{ml}$ high-fat emulsion). Much larger volume changes have been observed with higher calorie meals. A $70 \%$ gall bladder volume change was reported $45 \mathrm{~min}$ after a $465 \mathrm{kcal}$ mixed solid-liquid meal ${ }^{41}$ and $70 \%$ gall bladder volume change $70 \mathrm{~min}$ after a $675 \mathrm{kcal}$ fat emulsion test meal $^{8}$ in healthy subjects.

From the test-retest studies, we have also observed that the fasted gall bladder volume varied remarkably between individuals and that individual day-to-day variability can have wide coefficients of variation of up to $42 \%$. An influence of gender, age and body size on gall bladder volume has been reported from large surveys. ${ }^{42-44}$ Our mean fasted value of $26 \mathrm{ml}$ is higher than previously reported values in the $18-\mathrm{ml}$ range, ${ }^{37}$ and this could be because of imaging technology and/or subjects' cohort differences. One possible explanation for the large intraindividual variation in fasting gall bladder volumes is the cephalic phase response to food. The subjects may have been exposed to food-related sensory stimulation at home or on their way to the study site. Cephalic, pre-ingestive neural signals at the thought, sight or smell of food can trigger a number of physiological and secretory responses, ${ }^{45}$ while sham feeding clearly induces gall bladder emptying. ${ }^{46}$ Although in this study it was not possible to control the subjects' environment overnight before the morning measurements, future studies could consider this option in the study design. Gall bladder volume may also fluctuate with the cyclic variations of the migrating motor complex and motilin levels. ${ }^{47}$ We observed a correlation between gall bladder fasting volume size and individuals' body frame but this was not surprising. ${ }^{43}$

Because of the different volume, taste/aroma, color and texture of the samples, we could not exclude the presence of a possible ingestive cephalic component of gall bladder emptying in these data. One thought for future studies would be to manufacture the new test samples as equal in volume/texture/ flavor/color as possible. Cephalic effects could also help to explain the wide variation in time to maximum gall bladder volume change, which varied not just inter-subjects but also between study days. It is worth noting that in some of the experiments carried out the time to maximum gall bladder volume change was $65 \mathrm{~min}$, indicating that the volume change could possibly have been greater at later times than the period investigated. The time period investigated is a limitation of this study, and it would be desirable in future studies to extend the monitoring time window to at least 120 min to fully capture the time course of the emptying of the gall bladder. Intravenous infusion of $\mathrm{CCK}^{48}$ could be used as a gall bladder emptying standard for comparison.

In conclusion, various food ingredients are capable of inducing varying degrees of gall bladder emptying. Among the various food ingredients and actives tested here, fat and semi-skimmed milk induced the most profound volume changes. Fat showed the strongest effect, which correlated with plasma CCK levels. Improved knowledge of how to stimulate bile release using food ingredients will be useful to improve in vitro/in vivo correlation of bioavailability testing of hydrophobic drugs. It could improve performance of cholesterol-lowering plant stanol and sterol products and possibly aid understanding of some cholesterol gallstone disease.

\section{CONFLICT OF INTEREST}

The Nottingham team was the recipient of this research project grant from Johnson \& Johnson Consumer Services EAME Ltd. MR and RI are employees of Johnson \& Johnson Consumer Services EAME Ltd. The remaining authors declare no conflict of interest.

\section{ACKNOWLEDGEMENTS}

We are grateful for support from the Nottingham Digestive Diseases Biomedical Research Unit and its team of research nurses for blood taking.

\section{REFERENCES}

1 Baxter JN, Grime JS, Critchley M, Shields R. Relationship between gastric emptying of solids and gall bladder emptying in normal subjects. Gut 1985; 26: 342-351.

2 Shaffer EA. Review article: control of gall-bladder motor function. Aliment Pharmacol Ther 2000; 14: 2-8.

3 Fisher RS, Rock E, Malmud LS. Effects of meal composition on gallbladder and gastric emptying in man. Dig Dis Sci 1987; 32: 1337-1344.

4 Lawson M, Everson GT, Klingensmith W, Kern F. Coordination of gastric and gallbladder emptying after ingestion of a regular meal. Gastroenterology 1983; 85: 866-870.

5 Degen L, Matzinger D, Drewe J, Nissle S, Maecke $\mathrm{H}$, Lengsfeld $\mathrm{H}$ et al. Role of free fatty acids in regulating gastric emptying and gallbladder contraction. Digestion 2006; 74: 131-139.

6 Froehlich F, Gonvers JJ, Fried M. Role of nutrient fat and cholecystokinin in regulation of gallbladder emptying in man. Dig Dis Sci 1995; 40: 529-533.

7 Ledeboer M, Masclee AAM, Biemond I, Lamers C. Differences in cholecystokinin release and gallbladder contraction between emulsified and nonemulsified long-chain triglycerides. J Parenter Enteral Nutr 1999; 23: 203-206.

8 Marciani L, Wickham M, Singh G, Bush D, Pick B, Cox E et al. Enhancement of intragastric acid stability of a fat emulsion meal delays gastric emptying and increases cholecystokinin release and gallbladder contraction. Am J Physiol-Gastrointest Liver Physiol 2007; 292: G1607-G1613.

9 Liddle RA, Goldfine ID, Rosen MS, Taplitz RA, Williams JA. Cholecystokinin bioactivity in human plasma: molecular forms, responses to feeding and relationship to gallbladder contraction. J Clin Invest 1985; 75: 1144-1152.

10 Bowen J, Noakes M, Trenerry C, Clifton PM. Energy intake, ghrelin, and cholecystokinin after different carbohydrate and protein preloads in overweight men. J Clin Endocrinol Metab 2006; 91: 1477-1483.

11 Rasyid A, Lelo A. The effect of curcumin and placebo on human gall bladder function: an ultrasound study. Aliment Pharmacol Ther 1999; 13: 245-249.

12 Liddle RA. Regulation of cholecystokinin secretion in humans. J Gastroenterol 2000; 35: 181-187.

13 Douglas BR, Jansen J, Tham R, Lamers C. Coffee stimulation of cholecystokinin release and gallbladder contraction in humans. Am J Clin Nutr 1990; 52: 553-556.

14 Maldonado-Valderrama J, Wilde P, Macierzanka A, Mackie A. The role of bile salts in digestion. Adv Colloid Interface Sci 2011; 165: 36-46.

15 Shiau YF. Mechanisms of intestinal fat absorption. Am J Physiol 1981; 240: G1-G9.

16 Carey MC, Small DM. Micelle formation by bile salts: physical-chemical and thermodynamic considerations. Arch Intern Med 1972; 130: 506-527.

17 Amidon GL, Lennernas H, Shah VP, Crison JR. A theoretical basis for a biopharmaceutic drug classification: the correlation of in vitro drug product dissolution and in vivo bioavailability. Pharm Res 1995; 12: 413-420.

18 Kaukonen AM, Boyd BJ, Charman WN, Porter CJH. Drug solubilization behavior during in vitro digestion of suspension formulations of poorly water-soluble drugs in triglyceride lipids. Pharm Res 2004; 21: 254-260.

19 MacGregor KJ, Embleton JK, Lacy JE, Perry EA, Solomon LJ, Seager $\mathrm{H}$ et al. Influence of lipolysis on drug absorption from the gastro-intestinal tract. Adv Drug Deliv Rev 1997; 25: 33-46

20 Heinemann T, Kullakublick GA, Pietruck B, Vonbergmann K. Mechanisms of action of plant sterols on inhibition of cholesterol absorption: comparison of sitosterol and sitostanol. Eur J Clin Pharmacol 1991; 40: S59-S63.

21 Plat J, Mensink RP. Plant stanol and sterol esters in the control of blood cholesterol levels: mechanism and safety aspects. Am J Cardiol 2005; 96: 15D-22D.

22 Pauletzki J, Paumgartner G. Review article: defects in gall-bladder motor function - role in gallstone formation and recurrence. Aliment Pharmacol Ther 2000; 14: 32-34.

23 Annese V, Bassotti G, Caruso N, De Cosmo S, Gabbrielli A, Modoni S et al. Gastrointestinal motor dysfunction, symptoms, and neuropathy in noninsulindependent (type 2) diabetes mellitus. J Clin Gastroenterol 1999; 29: 171-177. 
24 Hidalgo L, Clave P, Estorch M, Rodriguez-Espinosa J, Rovati L, Greeley GH et al. Effect of cholecystokinin-A receptor blockade on postprandial insulinaemia and gastric emptying in humans. Neurogastroenterol Motility 2002; 14: 519-525.

25 Baxter JN, Grime JS, Critchley M, Shields R. Relationship between gastric-emptying of solids and gall- bladder emptying in normal subjects. Gut 1985; 26: 342-351.

26 Portincasa P, Moschetta A, Di Ciaula A, Palmieri VO, Milella M, Pastore G et al. Changes of gallbladder and gastric dynamics in patients with acute hepatitis $A$. Eur J Clin Invest 2001; 31: 617-622.

27 Degen LP, Peng FP, Collet A, Rossi L, Ketterer S, Serrano Y et al. Blockade of GRP receptors inhibits gastric emptying and gallbladder contraction but accelerates small intestinal transit. Gastroenterology 2001; 120: 361-368.

28 Goerg KJ, Spilker T. Effect of peppermint oil and caraway oil on gastrointestinal motility in healthy volunteers: a pharmacodynamic study using simultaneous determination of gastric and gall-bladder emptying and orocaecal transit time. Alimentary Pharmacol Ther 2003; 17: 445-451.

29 Di Ciaula A, Wang DQH, Portincasa P. Gallbladder and gastric motility in obese newborns, pre-adolescents and adults. J Gastroenterol Hepatol 2012; 27: 1298-1305.

30 Vyas PK, Vesy TL, Konez O, Ciavellara DP, Hua KD, Gaisie G. Estimation of gallbladder ejection fraction utilizing cholecystokinin-stimulated magnetic resonance cholangiography and comparison with hepatobiliary scintigraphy. J Magn Reson Imaging 2002; 15: 75-81.

31 Inoue $\mathrm{Y}$, Komatsu Y, Yoshikawa K, Akahane M, Isayama H, Ohtomo K et al. Biliary motor function in gallstone patients evaluated by fatty-meal MR cholangiography. J Magn Reson Imaging 2003; 18: 196-203.

32 Marciani L, Hall N, Pritchard SE, Cox EF, Totman JJ, Lad M et al. Preventing gastric sieving by blending a solid/water meal enhances satiation in healthy humans. J Nutr 2012; 142: 1253-1258.

33 Marciani L, Bush D, Wright P, Wickham M, Pick B, Wright J et al. Monitoring of gallbladder and gastric coordination by EPI. J Magn Reson Imaging 2005; 21: 82-85.

34 Marciani L, Coleman NS, Dunlop SP, Singh G, Marsden CA, Holmes GK et al. Gallbladder contraction, gastric emptying and antral motility: single visit assessment of upper Gl function in untreated Celiac disease using echo-planar MRI. J Magn Reson Imaging 2005; 22: 634-638.

35 Persson EM, Nilsson RG, Hansson GI, Lofgren LJ, Liback F, Knutson L et al. A clinical single-pass perfusion investigation of the dynamic in vivo secretory response to a dietary meal in human proximal small intestine. Pharm Res 2006; 23: 742-751.

36 Peters HPF, Foltz M, Kovacs EMR, Mela DJ, Schuring EAH, Wiseman SA. The effect of protease inhibitors derived from potato formulated in a minidrink on appetite, food intake and plasma cholecystokinin levels in humans. Int J Obes 2011; 35: $244-250$.
37 Rasyid A, Rahman ARA, Jaalam K, Lelo A. Effect of different curcumin dosages on human gall bladder. Asia Pacific J Clin Nutr 2002; 11: 314-318.

38 Feltrin $\mathrm{KL}$, Little TJ, Meyer JH, Horowitz M, AJPM Smout, Wishart J et al. Effects of intraduodenal fatty acids on appetite, antropyloroduodenal motility, and plasma CCK and GLP-1 in humans vary with their chain length. Am J Physiol Regul Integr Comp Physiol 2004; 287: R524-R533.

39 McLaughlin J, Luca MG, Jones MN, D'Amato M, Dockray GJ, Thompson DG. Fatty acid chain length determines cholecystokinin secretion and effect on human gastric motility. Gastroenterology 1999; 116: 46-53.

40 Liddle RA, Gertz BJ, Kanayama S, Beccaria L, Coker LD, Turnbull TA et al. Effects of a novel cholecystokinin (CCK) receptor antagonis, MK-329, on gallbladder contraction and gastic emptying in humans: implications for the physiology of CCK. J Clin Invest 1989; 84: 1220-1225.

41 Acalovschi M, Dumitrascu DL, Csakany I. Gastric and gall bladder emptying of a mixed meal are not coordinated in liver cirrhosis - A simultaneous sonographic study. Gut 1997; 40: 412-417.

42 Palasciano G, Portincasa P, Vinciguerra V, Velardi A, Tardi S, Baldassarre G et al. Gallstone prevalence and gallbladder volume in children and adolescents: an epidemmiological ultrasonographic survey and relationship with body mass index. Am J Gastroenterol 1989; 84: 1378-1382.

43 Palasciano G, Serio G, Portincasa P, Palmieri V, Fanelli M, Velardi A et al Gallbladder volume in adults and relationship to age, sex, body mass index and gallstones: a sonographic population study. Am J Gastroenterol 1992; 87: 493-497.

44 Portincasa P, Diciaula A, Baldassarre G, Palmieri V, Gentile A, Cimmino A et al. Gallbladder motor function in gallstone patients: sonographic and in-vitro studies of the role of gallstones, smooth muscle function and gallbladder wall inflammation. J Hepatol 1994; 21: 430-440.

45 Smeets PAM, Erkner A, de Graaf C. Cephalic phase responses and appetite. Nutr Rev 2010; 68: 643-655.

46 Hopman WPM, Jansen J, Rosenbusch G, Lamers C. Cephalic stimulation of gallbladder contraction in humans: role of cholecystokinin and the cholinergic system. Digestion 1987; 38: 197-203.

47 Luiking YC, Peeters TL, Stolk MFJ, Nieuwenhuijs VB, Portincasa P, Depoortere I et al. Motilin induces gall bladder emptying and antral contractions in the fasted state in humans. Gut 1998; 42: 830-835.

48 Byrnes DJ, Borody T, Daskalopoulos G, Boyle M, Benn I. Cholecystokinin and gallbladder contraction: effect of CCK infusion. Peptides 1981; 2: 259-262.

(c) (1) This work is licensed under a Creative Commons AttributionBY NC SA NonCommercial-ShareAlike 3.0 Unported License. To view a copy of this license, visit http://creativecommons.org/licenses/by-nc-sa/3.0/

upplementary Information accompanies this paper on European Journal of Clinical Nutrition website (http://www.nature.com/ejcn) 